\title{
Introduction to the Special Issue on Global Poverty Lines
}

\author{
Nora Lustig 1 Jacques Silber ${ }^{2,3}$
}

Received: 17 February 2016 / Accepted: 22 February 2016 / Published online: 23 April 2016

(C) Springer Science+Business Media New York 2016

In 2013, the World Bank adopted two new goals to guide its work: ending extreme poverty by 2030 and boosting shared prosperity. ${ }^{1}$ As part of the Sustainable Development Goals (SDGs), in 2015, the United Nations adopted the goal of eradicating extreme poverty for all people everywhere by $2030 .^{2}$ Monitoring progress and determining whether the goal of ending poverty is met crucially depends on how poverty is measured. In particular, it crucially depends on the global poverty line and how the line is adjusted over time. ${ }^{3}$ This special issue is dedicated to presenting alternative approaches to determine the global poverty line (or, more precisely, poverty lines) in order to measure the extent and evolution of extreme poverty in the developing world.

The first paper is by Ferreira et al. In "A Global Count of the Extreme Poor in 2012: Data Issues, Methodology and Initial Results", the authors meticulously describe how the new official World Bank global poverty line -announced in October 2015- of US $\$ 1.90$ per

\footnotetext{
${ }^{1}$ https://openknowledge.worldbank.org/handle/10986/20384.

${ }^{2}$ The first target of the SDGs describes the goal as follows: "By 2030, eradicate extreme poverty for all people everywhere, currently measured as people living on less than $\$ 1.25$ a day." For more details on the SDGs, see: http://www.un.org/sustainabledevelopment/poverty/.

${ }^{3}$ Some authors use the term "international poverty line (IPL)" instead of "global poverty line". In this Introduction, they are used interchangeably.

Jacques Silber

jsilber_2000@yahoo.com

Nora Lustig

nlustig@tulane.edu

1 Department of Economics, Tulane University, 6823 St. Charles Ave., 204 Tilton Hall, New Orleans, LA 70118, USA

2 Department of Economics, Bar-Ilan University, Ramat Gan, Israel

3 Senior Research Fellow, LISER (Luxembourg Institute of Socio-Economic Research),

Esch-sur-Alzette, Luxembourg
} 
day was calculated. In "Global Poverty Estimates Based on 2011 Purchasing Power Parity: Where Should the New Poverty Line be Drawn?", Kakwani and Son recommend the approach of equivalent poverty lines, but starting from the \$1.25 line in 2005 as the baseline rather than using the fifteen national poverty lines as the World Bank did to obtain the official poverty line. The papers by Jolliffe and Prydz "Estimating International Poverty Lines from Comparable National Thresholds" 4 and by Klasen et al. "International Income Poverty Measurement: Which Way Now?" take issue with the method (used by Ravallion et al. (2009), henceforth RCS), to select the fifteen poorest countries (in their sample) that were used as the reference group to calculate the World Bank official poverty lines of $\$ 1.25$ and the new $\$ 1.90$. Klasen et al. also propose an alternative to measuring global poverty, which relies on national poverty lines and inflation data, and does not use the PPP conversion factors. In his paper "Towards Better Global Poverty Measures", Ravallion emphasizes the notion of relative deprivation and how best to measure it. He discusses the use of a weakly relative poverty line, which is an absolute line up to some critical threshold but then rises afterwards with mean consumption. As an alternative, he suggests the use of two international poverty lines, one which would have a constant purchasing power and would be a lower bound to the global poverty line, and one which would be specific to the country and the period examined and would represent an upper bound to the global poverty line.

In what follows, we summarize and compare the methods proposed.

\section{One Frugal Line for all: The World Bank View}

In assessing extreme poverty in the developing world (including middle-income countries), the World Bank has long argued that "One Should Use a Line with Constant Purchasing Power and that it Should be Set at a Level that is Reasonably Representative of Low-income Countries, Making it an Explicitly Frugal Line" (Ravallion, this issue). The group of countries chosen to represent low-income countries has changed over time, except for the $\$ 1.90$ line launched in 2015 when the World Bank decided to explicitly keep the same countries that were used in 2008 (Ferreira et al., this issue).

The method followed to select the countries used as a reference group has varied over time. In 1990, the reference countries were: Kenya, Nepal, Tanzania, Bangladesh, Indonesia, Morocco, Philippines and Pakistan and the representative extreme poverty line was calculated "by inspection" (Ravallion et al. 1991). In 2001, the representative group included China, Tanzania, Zambia, India, Indonesia, Thailand, Nepal, Bangladesh, Tunisia and Pakistan, the official poverty line was the median of the poverty lines for this group. In 2008, the reference group included the fifteen poorest countries in the sample obtained by RCS of 74 countries which had data on national poverty lines from 1987 to 2005 . The fifteen countries were identified as a reference group because poverty lines showed no relationship with national average consumption at these countries' low levels of consumption (i.e. they were in the "flat part" of the regression of poverty lines on the log of per capita consumption)..$^{5}$ The reference group of countries obtained in this way included: Chad, Ethiopia, The Gambia, Ghana, Guinea-Bissau, Malawi, Mali, Mozambique, Nepal, Niger, Rwanda, Sierra

\footnotetext{
${ }^{4}$ An earlier paper by these authors, Jolliffe and Prydz (2015), and Ferreira et al. (2015 and this issue) use the same approach for setting the poverty line. The only reason the values differ is that some of the PovcalNet inflation data were updated between the release of the two documents.

${ }^{5}$ Strictly speaking, there were 20 countries in the flat part.
} 
Leone, Tajikistan, Tanzania, Uganda, and the official global poverty line was calculated as the mean of the respective poverty lines. In 2015, as stated, the same fifteen countries were used.

To generate a line with "constant purchasing power", the World Bank (and many others) rely on the purchasing power parity conversion factors obtained from the International Comparison Program (IPC). The IPC collects price data across as many countries as possible and estimates the Purchasing Power Parity (PPP) exchange rates. ${ }^{6}$ While these PPPs have been widely used in measuring global poverty, as Ravallion (this issue) notes: "There are Puzzling Changes in PPPs from one ICP Round to the Next and Concerns About the Appropriateness of the Methods Used. Lack of Public Access to the Primary Data has not Helped." We will come back to the implications of the "puzzling changes" below.

The approach followed by the World Bank gave rise to the so-called "dollar-a-day" poverty line (in PPP dollars) which evolved from $\$ 1.01$ in 1990 , to $\$ 1.08$ in 2001 , to $\$ 1.25$ in 2008 and, finally, to the $\$ 1.90$. Each poverty line was derived using different rounds of calculations of the PPP conversion factors produced by the ICP. The 1990, 2001, 2008 and 2015 official poverty lines relied on the 1985, 1993, 2005 and 2011 ICP rounds, respectively. Ferreira et al. (2015) present a useful overview of how each of these official World Bank poverty lines has been constructed (a summary can be found in their Table 1).

Changes in methodology and country coverage by the ICP have introduced quite a bit of instability in the estimates of global poverty and its regional distribution. ${ }^{7}$ As Klasen et al. (this issue) state "the revisions associated with the move to $\$ 1.25$ poverty line in 2005 prices changed the view on the level and distribution of global poverty in the world in a particularly drastic way. The global headcount rate of poverty in 1990 increased from $29 \%$ using \$1.08 (1993 ICP) to $43 \%$ using \$1.25 (2005 ICP); similarly, the rate of poverty was revised upwards in 2005 by some 7 percentage points. The difference implies that some 400 million more people ( 1.37 billion instead of 930 million) were now declared to be absolutely poor, compared to before. The level adjustments were particularly substantial in East Asia, followed by South Asia and Sub-Saharan Africa, while they were much smaller elsewhere. Fortunately, the rate of progress was not affected by much: "The Time Trends in Poverty Between 1981 and 2005 were Reported to be Much More Similar to Before.... While These Figures also Substantially Changed the Target for MDG1 (Halving Global Poverty Now Meant Moving from $43 \%$ to $21.5 \%$ Using the \$1.25 Poverty Line, Instead of Moving from $29 \%$ to $14.5 \%$ Using the \$1.08 Poverty Line), the Similar Trend Observed Using Both Lines did not Cause Serious Problems for Measuring Progress Towards MDG1" (Klasen et al.). ${ }^{8}$

Ravallion (this issue) also discusses the way PPP exchange rates are derived by those involved in the International Comparison Program (ICP). He also mentions some unsolved puzzle which can be detected when taking a close look at the data. On the one hand, one expects the price level index or PLI (the ratio of the PPP over the market exchange rate) to rise in countries experiencing sustained growth. This link has been called the "Dynamic Penn Effect" (DPE). Since India's economy grew between 2005 and 2011, its PLI should have risen, but de facto it fell. Such a downward drift has also been observed in other Asian countries. No solution to this puzzle has been given and the lack of openness of the ICP project, in particular with respect to access to its data, does not help. Ravallion acknowledges

\footnotetext{
${ }^{6}$ World Bank (2014).

${ }^{7}$ See Deaton (2010), for a critique of the 2005 PPP conversion factors.

${ }^{8}$ For a thorough discussion of the methodology utilized to update the global poverty line with the 2005 PPP results and its implications, see Chen and Ravallion (2010).
} 
that the ICP project, which publishes PPPs, was not launched to determine a global poverty line. He also mentions the fact that the ICP seems to underestimate the weight of food, another cause of concern given that PPP are used to determine the global poverty line.

In addition to the problems that are introduced by quality and comparability surrounding the PPP conversion factors, updating poverty numbers requires reliable data on movements in the consumer price index (CPI) for each country. As Ferreira et al. (this issue) show, in some countries, finding reliable CPIs is quite difficult, if not impossible, and interpolation methods need to be used.

\section{Striving to Preserve the Integrity of the Goal Posts: The World Bank's $\$ 1.90$ Poverty Line}

The instability in poverty numbers and their regional distribution introduced by the change from 1993 to 2005 PPP's, gave the World Bank pause. In particular, it was essential to not only avoid manipulation but also "the appearance of manipulation of the goal post" (Ferreira et al., this issue), by either making the goal harder or easier to reach. To contend with this challenge, Ferreira et al. state that "In Revising the Line, We have Sought to Minimize Changes to the Real Purchasing Power of the Earlier \$1.25 Line (in 2005 PPPs), so as to Preserve the Integrity of the Goalposts for International Targets such as the Sustainable Development Goals and the World Bank's Twin Goals - Which Were Set with Respect to that Line."

In order to be faithful to this principle, the World Bank team decided to keep the same reference countries as those used in 2008 to define the $\$ 1.25$ per day poverty line: Chad, Ethiopia, The Gambia, Ghana, Guinea-Bissau, Malawi, Mali, Mozambique, Nepal, Niger, Rwanda, Sierra Leone, Tajikistan, Tanzania, Uganda. ${ }^{9}$ Next, taking the original value of each national poverty line in 2005 PPP dollars as reported in RCS, the World Bank team converted these lines back to local currency units using the Private Consumption PPP conversion factors in the WDI (World Development Indicators). Next, the fifteen national poverty lines in local currency were converted from 2005 to 2011 prices (also in local currency) using the ratio of the respective CPI vis-à-vis their common base year (2011 CPI divided by the $2005 \mathrm{CPI}) .{ }^{10}$ Next, each of the fifteen lines in 2011 prices in local currency

\footnotetext{
${ }^{9}$ These fifteen countries would not necessarily have been the same ones in the "flat" portion of the curve if the method used by RCS had been extended using data up to 2015.

${ }^{10}$ The CPIs were obtained from POVCALNet which for $75 \%$ of the countries are the annual official nation consumer price index as reported in the WDI. In the remaining $25 \%$, the adjustments were as follows: “... in cases where surveys take place in specific months, or where inflation is high, PovcalNet uses monthly CPIs from official sources instead. These series are reported to PovcalNet by World Bank country and regional teams, citing official national sources. For example, from the LAC region, CPIs are primarily monthly series since survey fieldwork is undertaken during specific months of the year. For China and India, PovcalNet uses separate consumption distributions from rural and urban areas and we therefore also use these countries' urban and rural CPIs as deflators. Indonesia also reports separate rural and urban distributions, but no disaggregated deflator is available, so the national CPI is used. Last, for a small number of countries, PovcalNet uses alternative inter-temporal deflators estimated from price or unit value data in household surveys or other alternative sources. These are all countries where there is either no CPI data or there are concerns about the accuracy of the data for measuring changing price levels as experienced by poor people. Gimenez and Jolliffe (2014), for example, show a large divergence between CPI data for Bangladesh, survey-based measures of inflation for the poor, and implicit measures of inflation as assessed through official poverty lines. Nevertheless, the decision to deviate from the use of official CPI data is taken very conservatively. For this round, we have taken it only for seven countries and in each case only after detailed consultations with the relevant national statistical bodies and the country poverty economists of the World Bank. For the 2012 global poverty estimates, such deflators are used in Bangladesh, Cambodia, Ghana, Iraq, Lao, Malawi and Tajikistan." (Ferreira et al. 2015).
} 
was converted into 2011 PPP using the 2011 Private Consumption conversion factors shown in WDI. Finally, Ferreira et al. took the average of these fifteen lines. The average is equal to $\$ 1.88$ and it was rounded to $\$ 1.90$ for simplicity. ${ }^{11}$

This approach naturally raises a number of questions, which the authors of this paper acknowledge. The list of such problems is quite long. They concern various issues such as the wide heterogeneity of the surveys used in terms of the content of their questionnaire, the methodology implemented to measure household consumption or income, the fact that well-being (in the form of either consumption or income) is measured at the household rather than individual level and that the resulting database mixes income and consumption data. There are also differences between countries in the length of the recall period and the number of food items included in the survey questionnaires, and when microdata for some countries did not exist they were replaced by estimates derived from a parametrization of Lorenz curves obtained from grouped data. These issues, however, affect any global poverty comparisons and not only those calculated by the World Bank.

The paper by Ferreira et al. ends with a presentation of updated country-level estimates of poverty, regional poverty profiles and an examination of future prospects for ending extreme poverty (based on the new $\$ 1.90$ poverty line). A great relief, especially when compared with what occurred with the introduction of the $\$ 1.25$ poverty line in 2008 , is that the headcount ratios for the (developing) world totals (and practically all regions) were very similar with the $\$ 1.25$ line and the $\$ 1.90$ one. In 2011 , the headcount for the world was 14.5 and $14.1 \%$ using the $\$ 1.25$ and the $\$ 1.90$ lines, respectively (Ferreira et al., Table 5). The projections for 2030 yielded a headcount ratio of 4.9 and $4.2 \%$ using the $\$ 1.25$ (2014 update) and the $\$ 1.90$ (2015 update) lines, respectively (Ferreira et al., Figure A-5).

In essence, the World Bank used a notion similar to that of equivalent poverty lines proposed by Kakwani and Son (2014), which will be discussed below, but it applied it to the national poverty lines of the same fifteen countries that were used to generate the previous $\$ 1.25$ line. That is, in order to preserve the goal posts, as Ferreira et al. describe it, the World Bank's new official poverty line of $\$ 1.90$ was derived by ensuring that the poverty rates obtained for the fifteen reference countries would be the same regardless if one used the 2005 or 2011 PPP.

\section{The Concept of "Equivalent Poverty Lines": An Alternative Procedure to Update the Global Poverty Line}

In their paper "Global Poverty Estimates Based on 2011 Purchasing Power Parity: Where Should the New Poverty Line be Drawn?", Kakwani and Son recommend to move away from the World Bank's method followed erstwhile (but not in 2015) of anchoring a single global poverty line on the national poverty lines of the poorest countries (in the sample for which there is data on national poverty lines, that is) and propose an alternative approach using the concept of equivalent poverty lines. The basic idea of Kakwani and Son's proposal amounts to stating that poverty lines based on the 2005 and 2011 PPPs will be equivalent if they produce exactly the same poverty rates. Their suggested methodology is the following: take the global poverty line of $\$ 1.25$ per day in 2005 PPP dollars and convert it into the equivalent value for each country expressed in 2011 PPP dollars by multiplying the $\$ 1.25$ line by one plus the own inflation rate between 2005 and 2011 for each country and divide

\footnotetext{
${ }^{11} \mathrm{By}$ coincidence, this magnitude ( $\$ 1.90$ per day) is exactly the same one would obtain if the $\$ 1.25$ poverty line had been converted into local currency units for 101 developing countries with poverty data, the results being updated to 2011, converted then to PPP 2011 and finally averaged (see, Kakwani and Son, this issue).
} 
this by the ratio of the PPP conversion factors in 2011 over that in 2005. As a consequence, a country with a high inflation rate between 2005 and 2011 or one whose PPP exchange rate appreciated in 2011 relative to 2005 will have a higher equivalent poverty line in 2011.

With this method, one ends up with as many equivalent lines as the number of countries to which this method is applied. Thus, there is no single poverty line based on the new 2011 PPPs which is equivalent to the $\$ 1.25$ poverty line in 2005 PPP. Such a single global poverty line may however be generated by computing a weighted average of the different equivalent poverty lines, the weights being proportional to the countries' population. Using data for the 101 countries for which surveys and PPPs are available yields a poverty line of $\$ 1.93$ per day in 2011 PPP dollars. ${ }^{12}$ If instead of a weighted average, the new global poverty line is calculated as the simple mean, the result is a $\$ 1.90$ line, which by sheer coincidence is precisely the poverty line recommended recently by the World Bank.

Poverty rates and the number of poor are computed using the equivalent poverty lines for each country and the database PovcalNet. Interesting findings emerge from such an approach. India's poverty, for example, decreased to $23.63 \%$ while poverty in China increased to $8.27 \% .^{13}$ The gap in poverty incidence between these two countries has thus narrowed but remains important. It also appears that the reduction in the number of poor occurred largely in South Asia and Sub-Saharan Africa.

The main difference between Kakwani and Son and Ferreira et al. resides in that the World Bank's new official poverty line starts out by using the RCS original national poverty lines for the fifteen countries included in the reference group while Kakwani and Son start out from the single $\$ 1.25$ global poverty line, which is already an average value. To illustrate the difference, suppose that there are two countries. Each country has a national poverty line, $\mathbf{z}$, in 2005 PPP dollars, which equal 1 and 3; and PPP conversion factors, $\mathbf{d}$, that convert the value into 2011 PPP dollars which equal 10 and 30, respectively. The average of the national poverty lines in 2005 PPP dollars is 2 . Ferreira et al. approach updates this value to 2011 PPP dollars as follows: $(1 * 10+3 * 30) / 2=50$. In contrast, Kakwani and Son's approach updates this value to 2011 PPP dollars as follows: $(2 * 10+2 * 30) / 2=40$. Hence, the closeness observed in the actual values of the two poverty lines is a coincidence. ${ }^{14}$

Given that there are two global poverty lines depending on the methodology (the $\$ 1.90$ a day proposed by the World Bank and $\$ 1.93$ a day calculated by Kakwani and Son), is there a way to determine which one to choose? Kakwani and Son propose using the relative mean deviation, a widely used indicator to measure the distance between two vectors. For each poverty line, there is a vector of poverty rates for 126 countries. The equivalence of any two poverty lines can be measured by the absolute distance between their corresponding vectors of poverty rates. The relative mean deviation lies between 0 and 1 and the lower its value, the greater the equivalence. Kakwani and Son find that the relative mean deviation when one compares the poverty rates based on $\$ 1.90$ in 2011 PPP with those based on $\$ 1.25$ in 2005 PPP is $6.9 \%$, while it is $6.2 \%$ when one compares the poverty rates based on $\$ 1.93$ in 2011 PPP with those based on \$1.25 in 2005 PPP. Although the difference between the two indicators seems small, "given the sample size of 126 countries, the difference between $6.9 \%$ and $6.2 \%$ is statistically significant. Based on this criterion, the $\$ 1.93$ poverty line

\footnotetext{
${ }^{12}$ The authors use data for 101 countries instead of the 126 available in POVCALNet because the latter uses imputed prices for 25 countries as opposed to directly obtained CPIs - so these countries were dropped from the calculation of the global poverty line but not the poverty counts.

${ }^{13}$ These results are obtained when using the $\$ 1.93$ poverty line at 2011 PPPs. When using the $\$ 1.25$ IPL at 2005 PPPs, the headcount ratio in India was $24.67 \%$ and the one in China was $6.26 \%$.

${ }^{14}$ Dean Jolliffe provided this useful example by electronic mail (February 9, 2016).
} 
performs better than the $\$ 1.90$ poverty line. It should also be noted that if the World Bank had adopted the poverty line of $\$ 1.88$ instead of rounding it to $\$ 1.90$, the performance of the $\$ 1.93$ poverty line would have been even superior."

Poverty rates and the number of poor are computed using the equivalent poverty lines for each country and the database PovcalNet. The global (for the developing world) headcount ratio for 2011 with the $\$ 1.93$ poverty line is $17.51 \%$ (Kakwani and Son, Table 1). ${ }^{15}$

\section{Alternative Methods to Select the Reference Group}

In their paper "Estimating International Poverty Lines from Comparable National Thresholds", Jolliffe and Prydz suggest basing the new International Poverty Line (IPL) on a database that is larger in terms of country and temporal coverage, using a set of poverty lines that have greater compatibility than that selected by RCS and adopting a methodological approach that allows for easy updating. They argue that basing the IPL on more recent national poverty lines would reduce the impact of quality issues with the inflation data because the number of years that household survey data would need to be updated from the time of survey field work to the reference year for the IPL would be much smaller. Following a review of the well-known concerns about the way the global poverty line is currently determined, the authors propose to estimate implicit national poverty lines based on a combination of national poverty headcounts reported in the WDI database with corresponding consumption and income distributions available in the PovcalNet database and used for international poverty estimates. Such an approach considerably increases the number of countries for which national poverty thresholds are available and produces a series of poverty lines that are closer to the ICP reference year. In the authors words, they " $\ldots$ end up deriving 864 'implicit' national poverty lines for 129 countries which correspond to officially reported national poverty rates when applied to the PovcalNet per capita welfare measure. This is more than a tenfold increase over the number of poverty lines used by RCS."

Whether using a log-log or a level-level specification, Jolliffe and Prydz always find a positive and statistically significant relationship between national poverty lines and national household final consumption expenditure. They therefore do not adopt RCS's method to identify a group of reference countries by selecting those that were included in the "flat" part of the relationship because they do not find a range for which the slope is not significantly different from zero. Instead, they use a set of 115 poverty lines that were closest to the 2011 PPP reference period and selected two approaches to determine an IPL. First they divide the sample of these national poverty lines into quartiles based on the household final consumption expenditure (HFCE) data, obtaining a set of 29 , rather than 15 , poverty lines for the poorest quartile. The median of these poverty lines turns out to be $\$ 1.86$ while their mean is \$2.11 so that the IPL selected by the World Bank lies in fact within these bounds. The second approach uses the World Bank's income classification of countries. The median poverty line observed for the set of low-income countries turns out to be equal to \$1.91.

In their paper "International Income Poverty Measurement: Which Way Now?", Klasen et al. argue that the $\$ 1.25$ global poverty line released in 2008 , based on the new 2005 PPPs, was not really a revision of the previous $\$ 1.08$ one but a new poverty line because it was based on a different (and larger) sample of countries and new ICP data. What did not change is the empirical estimation procedure and the technique implemented "to inflate or deflate

\footnotetext{
${ }^{15}$ Ferreira et al. in their Table 5 give a headcount ratio for the whole world equal to $14.1 \%$ when the IPL is equal to $\$ 1.90$ at 2011 PPPs. There may be several reasons for such a difference. They do not use the $\$ 1.93$ poverty line, do not indicate the number of poor for the Middle East and North Africa, and have a much higher number of poor for Europe and Central Asia and may have used different data for the total population.
} 
the poverty line backwards or forwards in time and then use the household surveys of the respective years and the deflated poverty line to count the poor". The 2011 global poverty line on the contrary is an update because it used the same sample countries and the same estimation procedures as those of 2008.

Klasen et al. also examine the differences that exist in the regression results when the national poverty line is related to national mean consumption, when it is a function of the logarithm of national mean consumption, and when the dependent variable is the logarithm of national poverty lines and theexplanatory variable the logarithm of mean consumption. When Klasen et al. tried to replicate the exercise by RCS, similarly to Jolliffe and Prydz, they do not find a "kink." That is, they cannot find a significant threshold separating a horizontal or "flat" regression line from a portion with a positive slope, the assumption which was at the basis of RCS's approach that led to the selection of the fifteen countries that constituted the reference group both for the $\$ 1.25$ line in 2008 and the $\$ 1.90$ line in 2015 .

In contrast to Jolliffe and Prydz, however, Klasen et al. do find a "kink" in the regression when correcting for what they consider specification errors. According to the authors, there are additional econometric issues with RCS's specification such as heteroscedasticity and the fact that the variables are not distributed normally. This is why the authors are in favor of a regression linking the logarithm of the poverty line to the logarithm of mean consumption. They then show that such an approach with data from 2011 yields a reference group of fifteen countries (fourteen if they drop three outliers) and when taking the mean of their national poverty lines this yields a poverty line of $\$ 1.67$ (\$1.71) per day in 2011 PPP dollars. For the 15-countries based poverty line, the authors used the same countries as Ferreira et al. minus Nepal plus Burkina Faso; when using 14 countries, they only dropped Nepal.

Klasen et al. conclude that "It Appears that for All Countries, Except China and South Africa, Poverty Incidence and the Number of Poor is Lower in 2011 PPPs than in 2005 PPPs. Moreover, Making a Distinction Between Rural and Urban Areas in China, India and Indonesia, as does the World Bank, has an Important Impact on the Results. Given that the Reference Group of Countries did not Really Change, the Difference Between the Results Based on the 2005 and 2011 PPPs is Related to the Variation in the PPPs Estimates". The authors conclude that the ICP data can only be used for cross-section comparisons and should not be applied to inter-temporal comparisons. We will discuss their proposed alternative below.

\section{One Frugal Line for all: Summing up}

In essence, the differences regarding how to calculate the global poverty line refer to the choice of countries to use as reference to determine a frugal "global floor", whether the reference group should be changed every time new PPPs are released (as the World Bank did when it released the official poverty line in 1990, 2001 and 2008), and the baseline poverty lines used to update the global poverty line to the new year for which PPP conversion factors become available.

In Table 1, we compare the alternative methods proposed by authors in this special issue. ${ }^{16}$ As one can observe, the proposed lines range from $\$ 1.67$ to $\$ 1.93$ per day in 2011 PPP dollars. If one drops Klasen et al.'s, the range narrows to $\$ 1.86$ from $\$ 1.93$. Irrespective of the method used, the resulting global poverty lines are quite close for this round. Given their closeness, they are likely to yield similar global poverty rates. There is no guarantee that this would be the case if the same methods were applied with new rounds of information on national poverty lines, national inflation rates and PPPs.

\footnotetext{
${ }^{16}$ Ferreira et al. (Table 1) nicely summarize the methods used by the World Bank since the first line was posited to that of 2015 .
} 


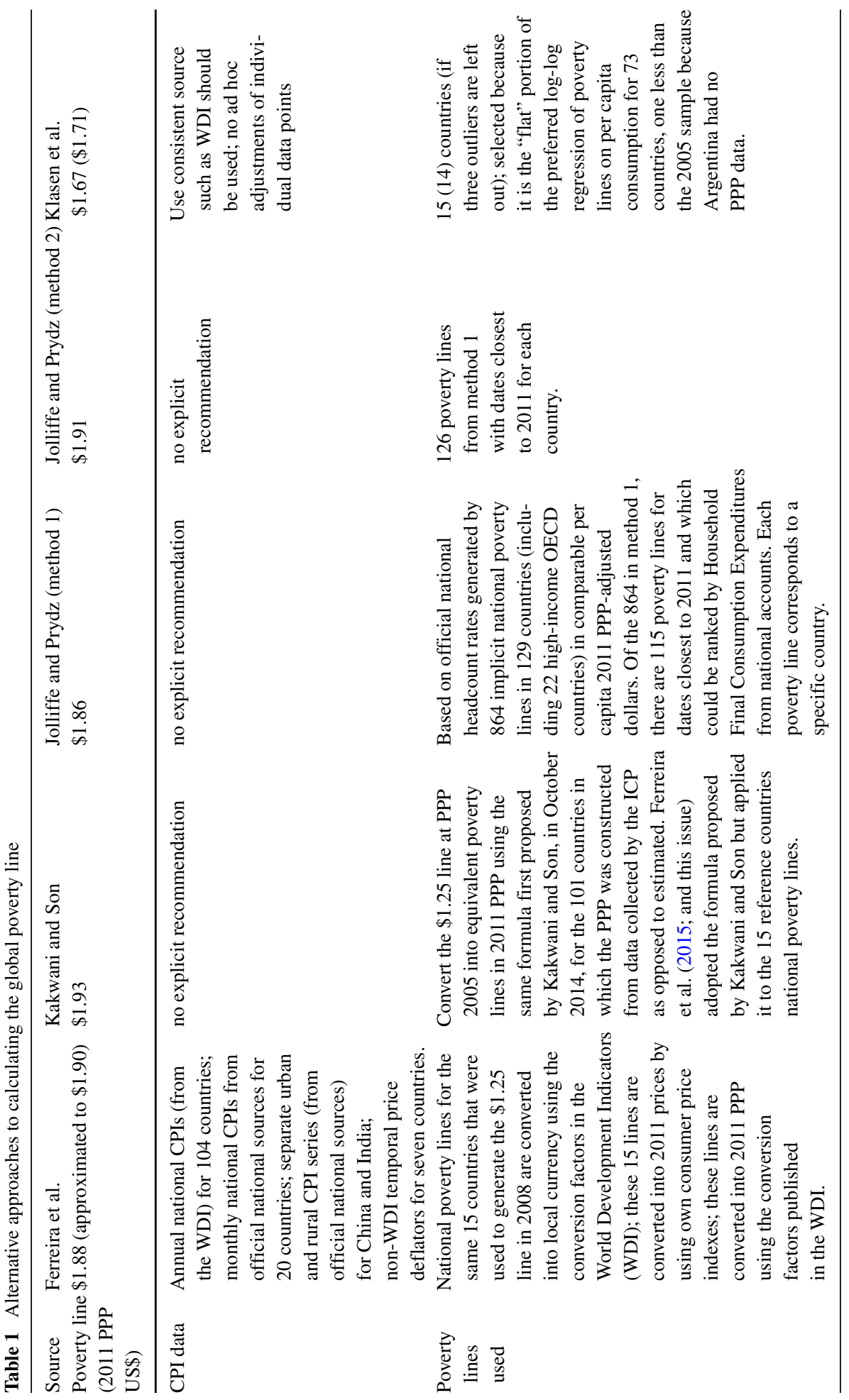




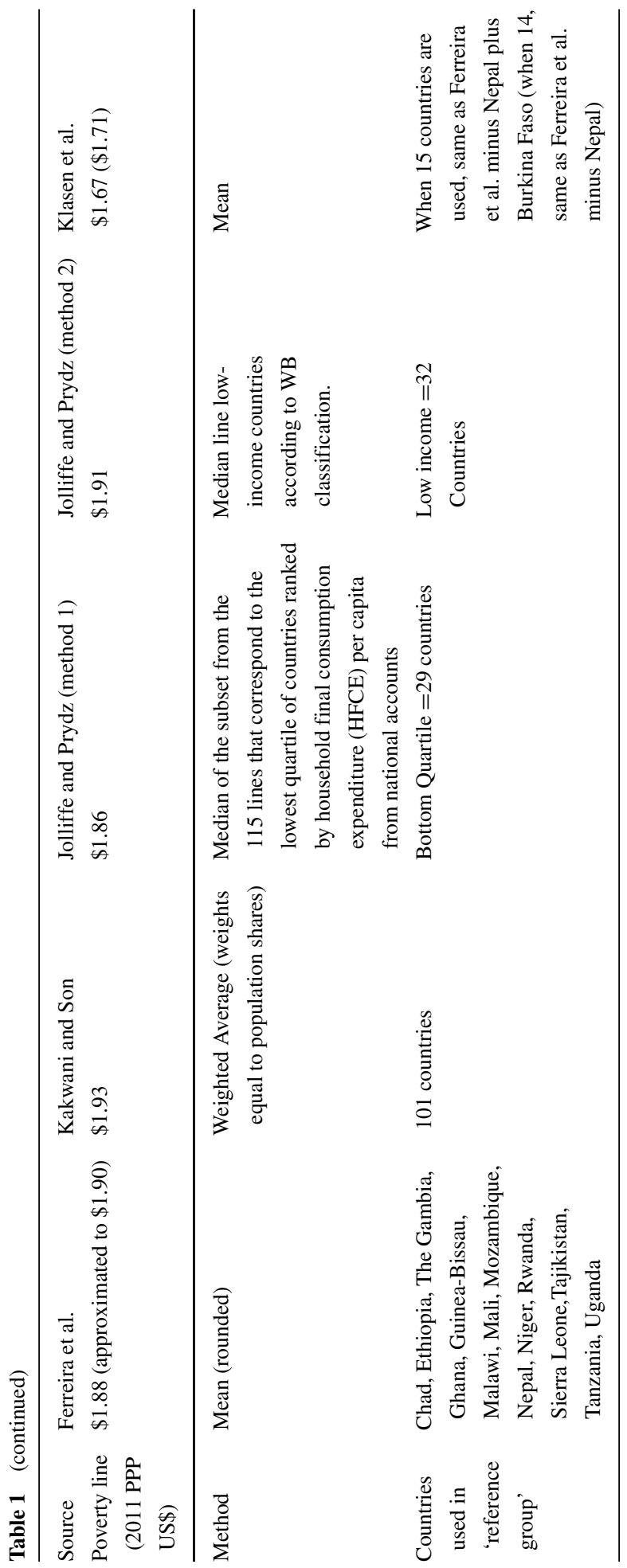




\section{Alternatives to the One-Frugal-Line-for-all}

The paper by Ravallion "Towards Better Global Poverty Measures" examines the case where welfare is assumed to be a function of both relative consumption and one's own consumption. Such an approach implies that there should be higher poverty lines in rich countries and that poverty measures derived from a fixed real line will overstate progress in the fight against poverty in growing economies. An important justification for using relative lines is the notion of relative deprivation, first introduced by sociologists and later on adopted by some economists. It should nevertheless be stressed that the costs of avoiding relative deprivation and social exclusion must have a positive minimum. This is why Ravallion introduced the concept of the weakly relative poverty line which is an absolute line up to some critical threshold but rises afterwards with mean consumption.

The author then asks whether weakly relative poverty lines are welfare-consistent. If higher poverty lines in richer countries reflect social effects on welfare, a welfare-consistent global absolute poverty line should rise with mean consumption. But the positive relationship between poverty lines and mean consumption may also be the consequence of the fact that welfare standards used in defining poverty are higher in richer countries. In such a case Ravallion argues that "An Absolute Measure in the Space of Welfare Requires a Fixed Real Poverty Line in the Income Space".

Ravallion believes that we do not know which of these two explanations is correct. This is why he raises the possibility of determining two international poverty lines, one which would have a constant purchasing power and would be a lower bound to the global poverty line, and one which would be specific to the country and the period examined and would represent an upper bound to the global poverty line implying that national poverty lines would reflect the cost of attaining a common level of welfare.

The second issue examined in this paper concerns the fate of the poorest in society. For the poorest not to be left behind there should be an increase in the lower bound to the distribution of standards of living. Identifying such a "consumption floor" is difficult, although biological floors have been estimated in the literature. But a "consumption floor" should be higher and in a recent paper Ravallion (2015) proposed a method to determine such a consumption floor.

Klasen et al. discuss the concept of weakly relative poverty line introduced by Ravallion and Chen in several papers. They stress that such an approach gives quite a different view of world poverty (e.g. weakly relative poverty is much higher in Latin America than absolute poverty) as well as of the pace of poverty reduction which is now much smaller. Such an approach has the advantage that poverty, when measured in the income space, is at least partially relative. The authors' recommendation is that such a weakly relative poverty line should have a fixed cost of survival plus a variable cost of social inclusion. Klasen et al. end their analysis by discussing a long term alternative to the actual procedure employed to determine a global poverty line. They favor a suggestion originally made by Altimir (1979) to the United Nations Economic Commission for Latin America and the Caribbean (UNECLAC) consisting of "creating national poverty lines using a procedure that is internationally consistent" so that poverty can then be aggregated across countries. In fact, this approach has been applied by UNECLAC as the official method to calculate poverty rates in Latin America and the Caribbean for decades. ${ }^{17}$

\footnotetext{
${ }^{17}$ While Klasen et al.'s suggestion was also made by Reddy and Pogge (2005), these authors did not realize that the idea was first proposed by the Argentine economist Oscar Altimir almost thirty years earlier and that the method is the one officially used by the UNECLAC.
} 


\section{The Way Forward}

The previous discussion shows how the construction of the global poverty line and measuring global poverty is fraught with data, normative and technical challenges. With the hope of generating a broad consensus and enhancing the reliability and credibility of poverty monitoring exercises, the World Bank created an independent Commission on Global Poverty in June 2015 under the leadership of Professor Anthony Atkinson. ${ }^{18}$ The remit of the Commission is to provide advice on two questions: (a) What should be the interpretation going forward of the definition of extreme poverty in real terms? (b) What choices should the World Bank make regarding complementary poverty measures to be tracked and made available to policy-makers? In other words, the Commission is charged with the quite specific technical question on how the World Bank measure of extreme poverty should be monitored between the present and 2030. The Commission is also charged with a broader mandate: what other kinds of poverty indicators should guide policy? Hopefully, the Commission will succeed in generating broadly accepted guidelines, both by researchers and users of the World Bank poverty statistics and the wider public concerned with the fate of the poor in developing and advanced countries.

\section{References}

Altimir, O.: La Dimensión de la pobreza en Latino América. Cuardernos de la CEPAL. CEPAL, Santiago (1979)

Chen, S., Ravallion, M.: The developing world is poorer than we thought, but no less successful in the fight against poverty. Q. J. Econ. 125(4), 1577-1625 (2010)

Deaton, A.: Price indexes, inequality, and the measurement of world poverty. Am. Econ. Rev. 100(1), 5-34 (2010)

Ferreira, F., Chen, S., Dabalen, A., Dikhanov, Y., Hamadeh, N., Joliffe, D., Narayan, A., Prydz, E.B., Revenga, A., Sangraula, P., Serajuddin, U., Yoshida, N.: A Global Count of the Exrteme Poor in 2012. World Bank Policy Research Working Paper No 7432 (2015)

Gimenez, L., Jolliffe, D.: Inflation for the poor: a comparison of CPI and household survey data. Bangladesh Dev. Stud. 37(1/2), 57-81 (2014)

Jolliffe, D., Prydz, E.B.: Global Poverty Goals and Prices: How Purchasing Power Parity Matters. Policy Research Working Paper, No. 7256. The World Bank, Washington, DC (2015)

Kakwani, N., Son, H.: Global Poverty Estimates Based on 2011 Purchasing Power Parity: Where Should the New Poverty Line be Drawn? Unpublished Paper, October 2014 (2014)

Ravallion, M.: Are the World's Poorest Being Left Behind? ECINEQ Working Paper 369 (2015)

Ravallion, M., Chen, C., Sangraula, P.: Dollar a day revisited. World Bank Econ. Rev. 23(2), 163-184 (2009). doi:10.1093/wber/lhp007

Ravallion, M., Datt, G., Walle, D.: Quantifying absolute poverty in the developing world. Rev. Income Wealth 37(4), 345-361 (1991)

Reddy, S., Pogge, T.: How not to count the poor, Version 6.2. Available at www.socialanalysis.org (2005)

World Bank: Purchasing Power Parities and Real Expenditures of World Economies. World Bank, Washington, DC (2014)

\footnotetext{
${ }^{18}$ http://www.worldbank.org/en/programs/commission-on-global-poverty.
} 